\title{
AVALIAÇÃO DA BALNEABILIDADE E IDENTIFICAÇÃO DA ICTIOFAUNA DO BALNEARIO DA AMIZADE DE PRESIDENTE PRUDENTE-SP
}

\author{
André Gonçalves Vieira ${ }^{1}$
}

\author{
Mariane Moura Andrade ${ }^{2}$
}

Luiz Waldemar de Oliveira ${ }^{3}$

\begin{abstract}
RESUMO
O Balneário da Amizade, localizado entre os municípios de Presidente Prudente e Alvares Machado/SP, vem passando por ações antrópicas (revitalização urbana). O local apresenta grande potencial turístico, sendo extremamente importante a avaliação da agua para balneabilidade, a área integra a bacia do Limoeiro mesma esta inserida nas bacias do Rio Santo Anastácio e Paranapanema. Neste estudo, foram realizadas análises da balneabilidade e identificação da ictiofauna, para analise de balneabilidade foram coletas amostras de agua em diferentes pontos de amostragem ao longo da represa, seguindo as recomendações da norma NBR-9897. O parâmetro indicador para a classificação quanto à sua balneabilidade foi a concentração de coliformes totais (CONAMA 357/05). Para a identificação da ictiofauna foram realizadas entrevistas juntos aos pescadores que frequentam o balneário. Dessa forma, este trabalho contribuirá para a formação de um banco de dados importante e inédito sobre os resultados de Balneabilidade e Ictiofauna da Represa, que poderão servir de base para o planejamento Turístico e Ambiental do Município de Presidente Prudente/SP.
\end{abstract}

PALAVRAS-CHAVE: Balneabilidade, Ictiofauna, Levantamento, E. coli, Meio Ambiente

\footnotetext{
${ }^{1}$ Biólogo pela Universidade do Oeste Paulista, Presidente Prudente - São Paulo; Mestrando em Geografia Profissional pela Universidade Estadual Paulista Júlio de Mesquita Filho, Presidente Prudente; Discente do curso de Especialização em Pericia e Auditoria Ambiental da Universidade Candido Mendes, Rio de Janeiro, RJ - São Paulo. E-mail: dre_goncalves@hotmail.com.

${ }^{2}$ Engenheira Florestal pela Universidade Tecnológica Federal do Paraná, Campus Dois VizinhosParaná e Pós-graduanda em MBA de Gestão Ambiental e Desenvolvimento Sustentável pela Universidade Centro de Ensino Superior de Maringá, Presidente Prudente- São Paulo. E-mail: enairamma@hotmail.com.

${ }^{3}$ Biólogo Me. Professor da Universidade do Oeste Paulista, Presidente Prudente - São Paulo. E-mail. oliveira@unoeste.br
} 


\title{
EVALUATION OF BATHING AND IDENTIFICATION ICHTHYOFAUNA IN BALNEARIO DA AMIZADE IN PRESIDENTE PRUDENTE-SP
}

\begin{abstract}
The Balneario da Amizade, located between the municipalities of Presidente Prudente and Alvares Machado / SP, has been going through human activities (urban renewal). The place has great potential for tourism is extremely important to evaluate the water for bathing, the area includes the basin of the Limoeiro same is inserted in the basins of the Rio Santo Anastacio and Paranapanema. In this study, analysis of bathing and identification of fish fauna were made for analysis of bathing water samples were collected at different sampling points along the dam, following the recommendations of NBR-9897 standard. The parameter indicator for classification as to their bathing was the concentration of total coliforms (CONAMA 357/05). To identify the fish fauna interviews were conducted together fishermen who frequent the resort. Thus, this work will contribute to the formation of a database important and unprecedented on the results of bathing and Ichthyofauna Dam, which may serve as a basis for Tourism and Environmental Planning of the Municipality of Presidente Prudente / SP.
\end{abstract}

KEYWORDS: bathing, Ichthyofauna, Survey, E. coli, Environment.

\section{EVALUACIÓN DE BAÑARSE Y IDENTIFICACIÓN DE LA ICTIOFAUNA EN LO BALNEARIO DE LA AMISTAD IN PRESIDENTE PRUDENTE-SP}

\section{RESUMEN}

El Balneario de la Amistad, que se encuentra entre los municipios de Presidente Prudente y Alvares Machado / SP, ha estado pasando por las actividades humanas (renovación urbana). El lugar tiene un gran potencial para el turismo es muy importante para evaluar el agua para el baño, la zona incluye la cuenca del Limoeiro misma se inserta en las cuencas del Río Santo Anastacio y Paranapanema. En este estudio, se realizaron análisis de baño y la identificación de la fauna de peces para el análisis de muestras de agua de baño se recogieron en diferentes puntos de muestreo a lo largo de la presa, siguiendo las recomendaciones de la norma NBR-9897. El indicador de parámetros para la clasificación en cuanto a su baño fue la concentración de coliformes totales (CONAMA 357/05). Para identificar las entrevistas fauna de peces se llevaron a cabo en conjunto pescadores que frecuentan el complejo. Por lo tanto, este trabajo contribuirá a la formación de una base de datos importante y sin precedentes en los resultados de baño y ictiofauna Dam, que puede servir de base para el Turismo y Planificación del Medio Ambiente de la Municipalidad de Presidente Prudente / SP.

PALABRAS CLAVE: baño, ictiofauna, la encuesta, E. coli, Medio Ambiente. 


\section{INTRODUÇÃO}

Ao longo da história do País, a cobertura florestal nativa, representada pelos diferentes biomas, foi sendo fragmentada e cedendo espaço para as culturas agrícolas, as pastagens e as cidades. (ALMEIDA, 1999). A noção de recursos naturais inesgotáveis e o modo de produção que impera no país estimularam e ainda estimulam a expansão da fronteira agrícola, ainda que se busque o aumento ou a manutenção da produtividade das áreas já cultivadas. Assim, o processo de fragmentação florestal foi intenso nas regiões economicamente mais desenvolvidas, o Sudeste e o Sul, e avança rapidamente para o Centro-Oeste e Norte, ficando a vegetação representada por florestas secundárias, em vários estados de degradação, salvo algumas reservas de florestas bem conservadas.

Além de depreciar a fauna e flora aquática, a poluição dos recursos hídricos causada por ações antrópicas, pode acarretar inúmeros problemas à saúde humana, pois a água é empregada como veículo pelos agentes patogênicos na disseminação de doenças (GREGHI, 2005).

A qualidade da água é um termo que não se restringe à determinação da pureza da mesma, mas às suas características desejadas para os seus diversos usos. Tanto as características físico-químicas quanto as biológicas da água podem ser alteradas. (BILICH; LACERDA, 2005).

Para caracterizar esta qualidade, foram realizadas análises da balneabilidade o parâmetro indicador para a classificação quanto à sua balneabilidade em termos sanitários foi o número de coliformes totais...

Segundo a CETESB (2004), balneabilidade é a qualidade das águas destinadas à recreação de contato primário(direto e prolongado)com a água, onde a possibilidade de ingerir quantidades apreciáveis de água é elevada. As águas recreacionais contêm geralmente uma mistura de microrganismos patogênicos e não patogênicos, que podem ser derivados dos efluentes do esgoto, do uso pela população e animais.

Além disso, podem também conter microrganismos patogênicos de vida livre, que causam infecções gastrointestinais após ingestão, ou infecções respiratórias (WHO, 2003). 
Segundo a Resolução CONAMA 274/00, que trata especificamente da balneabilidade, a qualidade das águas doces, salobras e salinas destinadas à balneabilidade terá sua condição avaliada nas categorias própria e imprópria. As águas consideradas próprias poderão ser subdivididas em: Excelente, Muito Boa e Satisfatória. As águas são consideradas impróprias quando ultrapassarem os índices bacteriológicos admitidos, presença de resíduos como esgotos sanitários e outras substâncias capazes de oferecer riscos à saúde, floração de algas ou outros organismos ou presença de transmissores potenciais de doenças de veiculação hídrica.

Sabe-se que áreas de balneabilidade acabam sendo lugares de pesca para algumas pessoas, a América do Sul contém a mais rica ictiofauna de água doce do mundo, porém a avaliação e compreensão dessa rica diversidade são negativamente afetadas pelo conhecimento incompleto de sua ecologia, biologia e sistemática (MENEZES, 1996). Schaefer (1998) estimativa o impressionante número de 8.000 espécies, o que, proporcionalmente, representa um oitavo de toda a biodiversidade estimada de vertebrados viventes na América do Sul (VARI \& MALABARBA, 1998). A segunda bacia hidrográfica mais importante do Brasil em termos de área e diversidade ictiofaunística é a bacia do Paraná - Paraguai Uruguai. Apesar dessa grande diversidade, com aproximadamente 500 espécies, sua composição não é completamente conhecida; além disso, sua ictiofauna tem sido impactada por uma série de atividades antrópicas deletérias não sustentáveis (MENEZES, 1988).

Em território brasileiro, a bacia do Alto rio Paraná drena os Estados de São Paulo, Paraná, Minas Gerais, Mato Grosso do Sul e Goiás (SOUZA FILHO \& STEVAUX, 1997), sendo que no Estado de São Paulo são registradas 22 famílias e aproximadamente 160 espécies de peixes (CASTRO \& MENEZES, 1998).

A maior parte dessa fauna é composta por espécies de peixes de pequeno porte que habitam pequenos riachos de cabeceiras, apresentando elevado grau de endemismo, dependentes da vegetação ripária para alimentação, reprodução e abrigo, havendo ainda muito que ser explorado nestes ambientes. Tais comunidades têm sido fortemente afetadas pela construção de barragens; usos descontrolados de pesticidas e fertilizantes; destruição de florestas, principalmente da vegetação 
ripária; assoreamentos e introdução de espécies de outras bacias hidrográficas (MENEZES, 1996; CASTRO \& MENEZES, 1998).

Dessa forma, riachos e cabeceiras são ambientes que devem receber prioridade em sua exploração (CASTRO \& MENEZES, 1998). Dessa forma observou-se a necessidade de um estudo na Represa do Balneário da Amizade que está localizada na bacia do alto curso do córrego do Limoeiro, que encontra-se na bacia hidrográfica do Rio Santo Anastácio que desagua no Rio Paraná próximo a cidade de Presidente Epitácio. A escolha da Represa do Balneário da Amizade para o estudo se dá devido ser um espelho d’água propício à natação, mergulho, prática da pesca e esportes aquáticos.

\section{METODOLOGIA}

\section{1 Área De Estudo}

Figura 2. Represa Balneário da Amizade.

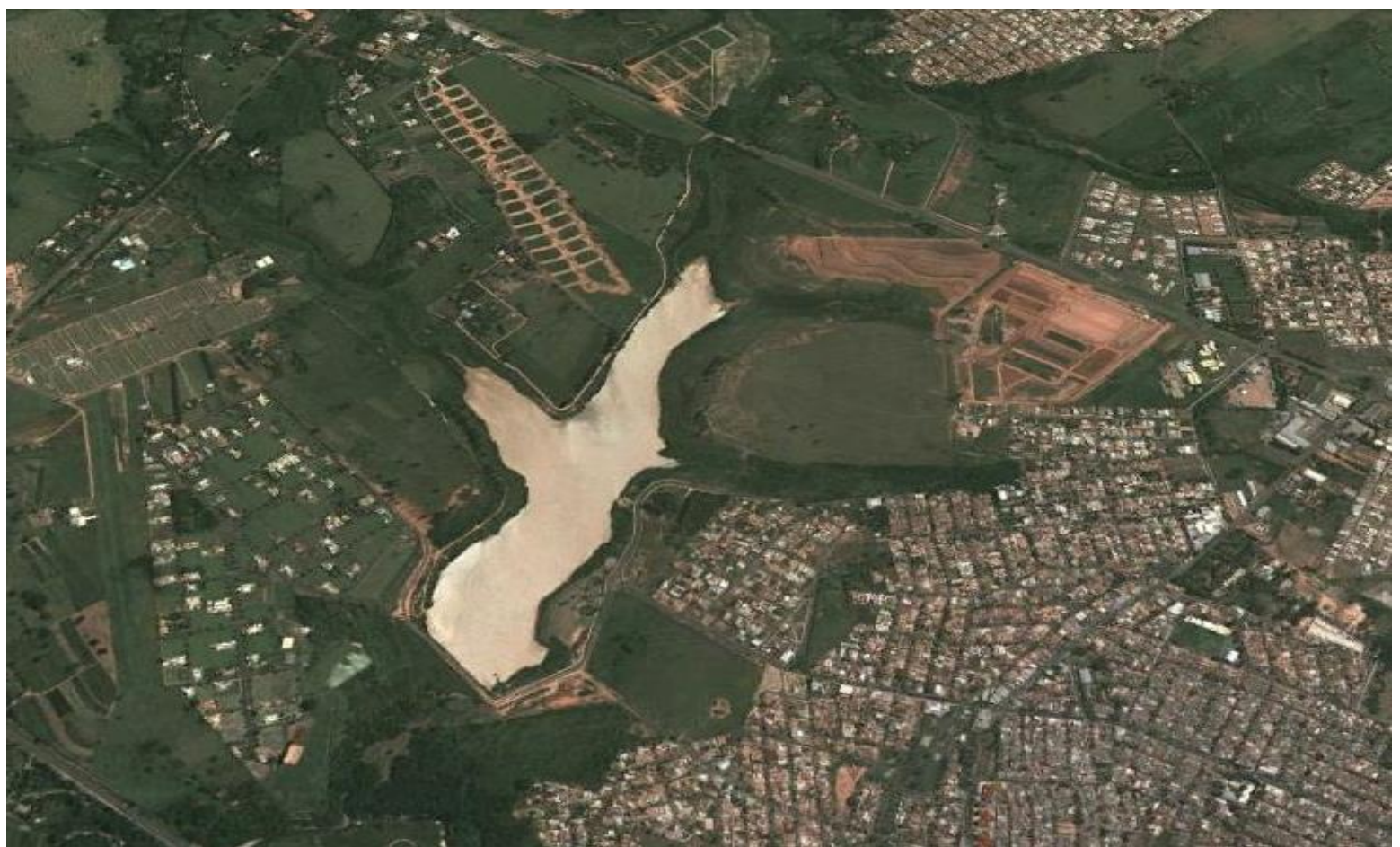

Fonte: Google Earth. 
A escolha da Represa do Balneário da Amizade para o estudo se da devido a mesma voltar a ser lugar de laser aos munícipes da região segundo o DECRETO № 25.398/2015 de Presidente Prudente "Dispõe sobre a regulamentação do uso e espaço do Balneário da Amizade, e dá outras providências. Nesta perspectiva optou-se por um trabalho com objetivo de estudo, avaliar o Índice de Balneabilidade e ictiofauna da Represa do Balneário da Amizade, a fim de identificar as espécies de peixes.

A bacia do Balneário da Amizade possui uma área de drenagem de 19,24 $\mathrm{Km}^{2}$, tendo suas coordenadas geográficas: $22^{\circ} 06^{\prime} 26,04^{\prime \prime S}$ de latitude e $51^{\circ} 26^{\prime} 43,50$ ”W de longitude. Está inserida na bacia do alto curso do córrego do Limoeiro, que por sua vez encontra-se na bacia hidrográfica do Rio Santo Anastácio, na divisa dos municípios de Presidente Prudente e Álvares Machado, a bacia do Balneário da Amizade é atravessada, de leste a oeste, pela Estrada Intermunicipal Arthur Boigues Filho, que liga os municípios citados.

\subsection{Metodologia Empregada}

Inicialmente foram realizadas revisões bibliográficas, entrevistas com munícipes que frequentam a área e levantamentos de dados disponíveis necessários ao trabalho.

Os pontos de coleta da água para análise foram delimitados de acordo com a NBR-9897, que dispõe sobre "Planejamento de amostragens de efluentes líquidos e corpos receptores", para verificar as condições da água da represa baseou-se nas Resoluções CONAMA n. 274/00 e n. 357/05; e a partir das informações obtidas, diagnosticar a viabilidade da balneabilidade.

As amostras foram coletadas no período de 12 de janeiro a 09 fevereiro de 2015 de acordo com a NBR-9897, de modo sub-superficial, a aproximadamente 20 $\mathrm{cm}$ de profundidade, coletando-se um litro de água em cada ponto, sendo um total de 3 pontos, sendo realizada cinco coletas distribuídas no período acima com o total de 15 coletas nos seguintes pontos. Ponto 1 com coordenadas geográficas:

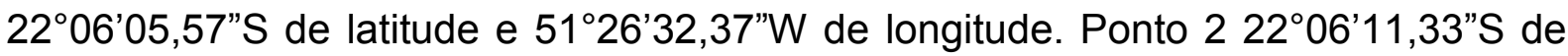
latitude e $51^{\circ} 26^{\prime} 34,43^{\prime \prime} \mathrm{W}$ de longitude e o Ponto $322^{\circ} 06^{\prime} 23,45^{\prime \prime} S$ de latitude e $51^{\circ} 26$ '39,63"W de longitude para encaminhamento a Divisão de Laboratórios de 
Marília - SP (EDM), onde foram realizadas as seguintes análises para o Índice de Balneabilidade (Coliformes totais e Escherichia coli).

A classificação das águas para balneabilidade segue o parâmetro do número de coliformes totais, indicado nas Resoluções CONAMA $n^{\circ}$. 274/00 e $n^{\circ}$. 357/05, sendo as categorias como próprias (excelente, muito boa ou satisfatória) ou impróprias. Assim a água amostrada em cada ponto de coleta é enquadrada nas categorias citadas acima no Quadro 1.

Tabela 1: Classificação das águas para balneabilidade, segundo limite de coliformes totais (Resolução CONAMA 274/00). NMP: número mais provável.

\begin{tabular}{|c|c|c|c|c|c|}
\hline Categoria & $\begin{array}{l}\text { Porcentage } \\
\text { m do tempo }\end{array}$ & $\begin{array}{c}\text { Limite de } \\
\text { Coliforme Fecal } \\
\text { (NPM/100ml) }\end{array}$ & $\begin{array}{c}\text { Limite de } \\
\text { Escherichia coli } \\
\text { (UFC/100ml) }\end{array}$ & $\begin{array}{l}\text { Limite de } \\
\text { Enterococos } \\
\text { (UFC/100ml) }\end{array}$ & $\begin{array}{c}\text { Limite de } \\
\text { Coliformes } \\
\text { Totais } \\
\text { (UFC } / 100 \mathrm{ml} \text { ) }\end{array}$ \\
\hline \multicolumn{6}{|c|}{ PRÓPRIA } \\
\hline Excelente & \multirow{3}{*}{$\begin{array}{l}\text { Valor máximo } \\
\text { em } 80 \% \text { ou } \\
\text { mais do } \\
\text { tempo }\end{array}$} & 250 & 200 & 25 & \\
\hline Muito Boa & & 500 & 400 & 50 & \\
\hline $\begin{array}{l}\text { Satisfatóri } \\
\text { a }\end{array}$ & & 1000 & 800 & 100 & \\
\hline \multicolumn{6}{|c|}{ IMPRÓRIA } \\
\hline \multicolumn{2}{|c|}{$\begin{array}{c}\text { Superior ao valor indicado } \\
\text { em } 20 \% \text { do tempo }\end{array}$} & 1000 & 800 & 100 & \\
\hline \multicolumn{2}{|c|}{$\begin{array}{l}\text { Superior ao valor indicado } \\
\text { na última amostragem }\end{array}$} & 2500 & 2000 & 400 & 5000 \\
\hline
\end{tabular}

Fonte: RES. CONAMA 274/00 e CONAMA 357/05.

Figura 2: Represa Balneário da Amizade com seus respectivos pontos de coleta para análise da água. 


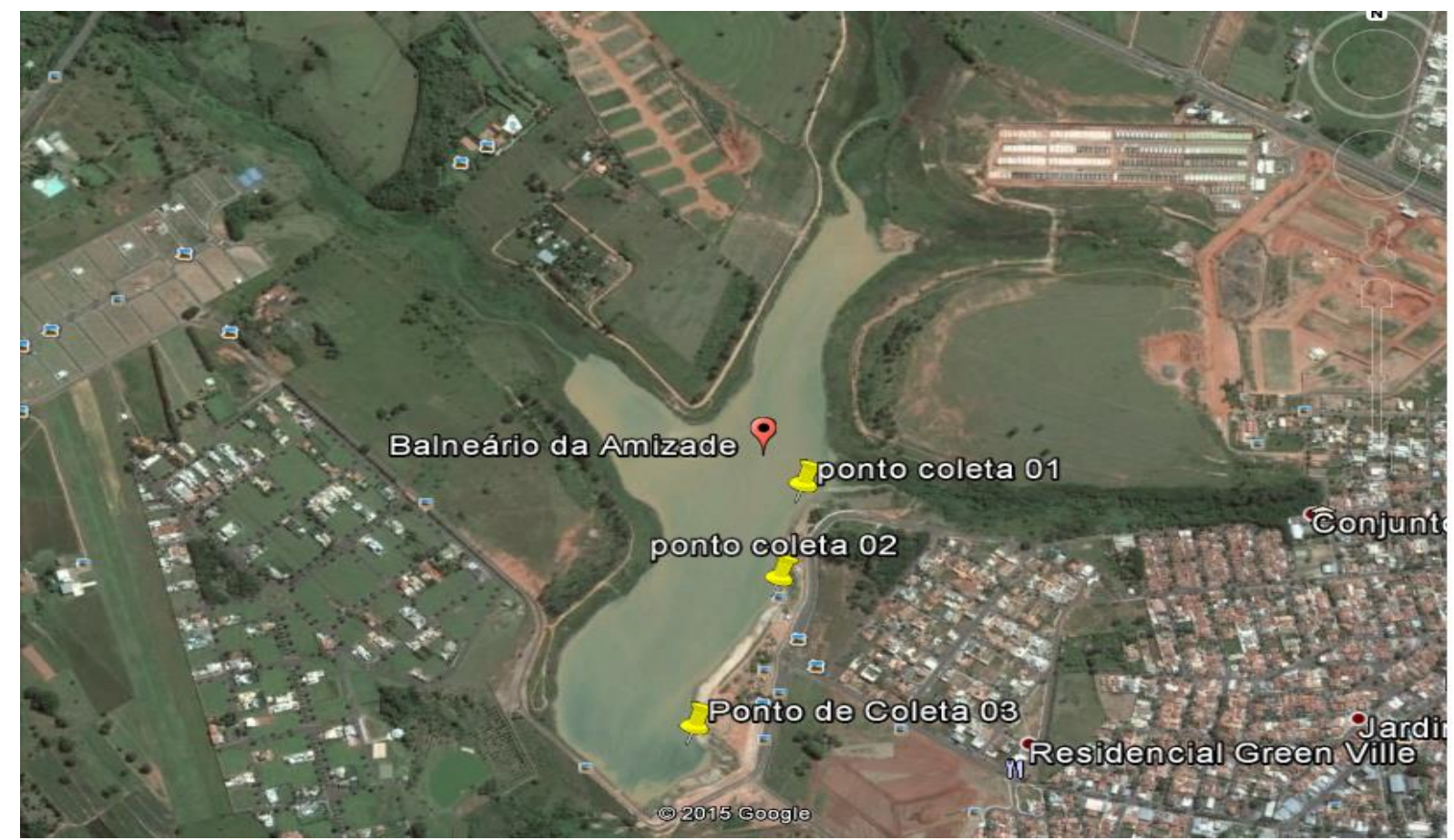

Fonte: Google Earth.

Para o levantamento e identificação das espécies de peixes ali existente, foram realizadas entrevistas com pessoas que frequentam a área para pesca e mediante nomes populares foram cruzadas informações cientificas e mediante imagens obtidas em livros e trabalhos científicos foram apresentados aos pescadores entrevistados onde confirmou-se ou não a espécie citada. $O$ levantamento de identificação se deu no mesmo período de coletas de balneabilidade.

\section{RESULTADOS E DISCUSSÃO}

O resultado microbiológico da qualidade da água do Balneário da Amizade, destinada a recreação de contato primário, revelou que a água nas amostras 1, 2 e 3 (Período mais chuvoso) estão classificados como própria (excelente) para o banho com pico de (90 UFC. $100 \mathrm{~mL}^{-1}$ ) no ponto 3 , uma vez comparada com os valores estabelecidos pela resolução 274/00 (quadro 1) a mesma encontra-se própria.

A água com destino para recreação de contato primário é classificada como própria quando atende aos critérios estabelecidos para as mesmas e não encontre 
outros fatores capazes de oferecer riscos à saúde humana ou torna-la desagradável à recreação (REGO; BARROS; SANTOS, 2010).

Outros estudos que avaliaram a qualidade da água para fins recreativos revelaram que durante a estação chuvosa há um aumento na quantidade de coliformes, pois águas pluviais, ao escoarem pelo solo, podem carrear impurezas para os corpos hídricos superficiais, comprometendo, dessa maneira, a qualidade das águas nos balneários. Tal situação não foi verificada no período chuvoso do presente estudo, pois, mesmo com a presença de chuvas não houve uma grande quantidade de Coliformes totais e Escherichia coli (MORAIS; SILVA, 2012). Os resultados obtidos neste estudo foram diferentes ao estudo realizado por Moura; Assumpção; Bischoff (2009), que ao realizarem o monitoramento microbiológico da água do Rio Cascavel-PR, obtiveram resultados que demonstraram um aumento na contagem, tanto de Coliformes totais e Escherichia coli.

$\mathrm{Na}$ bacia da Represa Balneário da Amizade obteve os seguintes resultados para o levantamento da ictiofauna (tabela 1).

Tabela 1. Classificação das espécies ictiofauna do Balneário da Amizade.

\begin{tabular}{|l|l|l|l|}
\hline Família & Nome Cientifico - Espécie & Nome Popular & $\begin{array}{l}\text { Origem (Nativo ou } \\
\text { Exótico) }\end{array}$ \\
\hline Acestrorhynchidae & Acestrorhynchus lacustris & Peixe-cachorra & Nativo \\
\hline Anostomidae & Leporinus sp & Piauçu & Nativo \\
\hline Callichthyidae & Callichthys callichthys & Caborja & Nativo \\
\hline \multirow{5}{*}{ Characidae } & Astyanax sp & Lambari & Nativo \\
\cline { 2 - 4 } & Moenkhausia Intermedia & Lambari Corinthiano & Nativo \\
\cline { 2 - 4 } & Piaractus mesopotamicus & Pacu-caranha & Nativo \\
\cline { 2 - 4 } & Serrasalmus spilopleura & Piranha-doce & Nativo \\
\hline \multirow{5}{*}{ Cichlidae } & Cichla monoculus & Tucunaré & Nativo \\
\cline { 2 - 4 } & Cichlasoma paranaense & Cará & Nativo \\
\cline { 2 - 4 } & Crenicichla sp & Jacundá & Nativo \\
\cline { 2 - 4 } & Geophagus brasiliensis & Acará & Nativo \\
\cline { 2 - 4 } & Oreochromis niloticus & Tilápia & Exótica \\
\hline Crenuchidae & Characidium sp & Mocinha & Nativo \\
\hline \multirow{3}{*}{ Curimatidae } & Steindachnerina insculpta & $\begin{array}{l}\text { Sagüiru-rabo- } \\
\text { amarelo }\end{array}$ & Nativo \\
\cline { 2 - 4 } & Cyphocharaxnagelii & Sagüiru & Nativo \\
\hline Cyprinidae & Cyprinus carpio & Carpa & Exótica \\
\hline Erythrinidae & Hoplias malabaricus & Traíra & Nativo \\
\hline Gymnotidae & Gymnotus carapo & Tuvira & Nativo \\
\hline Heptapteridae & Rhamdia quelen & Jundiá & Nativo \\
\hline \hline
\end{tabular}




\begin{tabular}{|l|l|l|l|}
\cline { 2 - 4 } & Hypostomus ancistroides & Cascudo & Nativo \\
\cline { 2 - 4 } & Hypostomus $s p$ & Acari & Nativo \\
\cline { 2 - 4 } & Loricaria sp & cascudo chinelinho & Nativo \\
\hline Pimelodidae & $\begin{array}{l}\text { Pseudoplatystoma } \\
\text { corruscans }\end{array}$ & Pintado & Nativo \\
\hline Poeciliidae & Phalloceroscaudimaculatus & Barrigudinho & Nativo \\
\hline Prochilodontidae & Prochilodus lineatus & Curimbatã & Nativo \\
\hline Synbranchidae & Synbranchus marmoratus & Mussum & Nativo \\
\hline
\end{tabular}

Foram identificadas 26 espécies de peixes, pertencentes a 16 famílias (Tabela 1), sendo 24 espécies nativas e 2 exóticas, a classificação de exótica compreendeu-se aquelas que não ocorrem geograficamente natural no território Brasileiro e nativa as que encontram-se naturalmente no território Brasileiro. Em termos de número de família, as mais representativas para a ictiofauna do Balneário da Amizade foram Cichlidae e Characidae compreendendo 11 espécies.

O presente estudo corrobora com composição ictiofaunística, com dominância absoluta de Cichlidae e Characidae, tais resultados vêm refletir aquela esperada para riachos não estuarinos da região neotropical (Castro, 1999), também registrada em riachos da Amazônia (Sabino \& Zuanon, 1998), na bacia do rio São Francisco (Casatti \& Castro, 1998), no leste do Brasil (Bizerril, 1994), na Mata Atlântica (Sabino \& Castro, 1990) e no Alto Paraná (Castro \& Casatti, 1997; Pavanelli \& Caramaschi, 1997). Rosa e Groth, 2004 classificam a espécie tilápia (Oreochromis niloticus) e a carpa (Cyprinus carpio) em rios, lagos e açudes, brasileiros como especeis invasoras introduzidas pelo homem não sendo nativa, porem distribuídas em todo território nacional.

\section{CONCLUSÃO}

De forma geral, a Represa Balneário da Amizade apresentou ótima condição nos três pontos de coletas para balneabilidade. Essa condição atribui-se aos não lançamentos de efluentes de rede de esgoto doméstico no local e a revitalização que a área recebeu. Apesar dos instrumentos e políticas para a manutenção da qualidade da água, o monitoramento e a fiscalização, são indispensáveis, e devem 
fazer parte do grupo de ações que tanto a prefeitura quanto o estado devam se atentar. A ictiofauna apresenta diversidade no lago, porem espécies invasoras devam ser retiradas devido proporcionar desequilíbrio ambiental. A realização de estudos sobre espécies endêmicas regionais faz necessário, pois espécie que não ocorre geograficamente na região vem causando danos nos ecossistemas.

\section{REFERÊNCIAS BIBLIOGRÁFICAS}

ABNT - ASSOCIAÇÃO BRASILEIRA DE NORMAS TÉCNICAS. NBR 9897: Planejamento de amostragem de efluentes líquidos e corpos receptores. Jun., 1987.

ALMEIDA, Josimar Ribeiro de [et al]. Planejamento Ambiental. Caminho para participação popular e gestão ambiental para nosso futuro comum: uma necessidade, um desafio. 2 ed. - Rio de Janeiro: Thex Ed.: Biblioteca Estácio de Sá, 1999.

BILICH, M. R.; LACERDA, M. P. C. Avaliação da qualidade da água do Distrito Federal (DF), por meio de geoprocessamento. Anais. XII Simpósio Brasileiro de Sensoriamento Remoto, Goiânia, Brasil, 16-21 abril 2005, INPE, p. 2059-2065.

BIZERRIL, C.R.S.F. Análise taxonômica e biogeográfica da ictiofauna de água doce do leste brasileiro. Acta Biol. Leopoldensia, 1994, 16:51-80.

CASATTI, L. \& CASTRO, R.M.C. A fish community of the São Francisco River headwaters riffles, southeastern Brazil. Ichthyol. Explor. Freshwaters, 1998, 9:229-242.

CASTRO, R.M.C. Evolução da ictiofauna de riachos sul-americanos: padrões gerais e possíveis processos causais. In Ecologia de Peixes de Riachos: Estado Atual e Perspectivas (E.P. Caramaschi, R. Mazzoni, C.R.S.F. Bizerril, P.R. Peres-Neto, eds.). Oecologia Brasiliensis, v. VI, Rio de Janeiro, 1999, p. 139-155.

CASTRO, R.M.C. \& MENEZES, N.A. Estudo diagnóstico da diversidade de peixes do Estado de São Paulo. In Biodiversidade do Estado de São Paulo, Brasil: Síntese do conhecimento ao final do século XX, 6: vertebrados (R.M.C. Castro, ed.). WinnerGraph, São Paulo, 1998, p. 1-13.

CASTRO, R.M.C. \& CASATTI, L. The fish fauna from a small forest stream of the upper Paraná River basin, Southeastern Brasil. Ichthyol. Explor. Freshwaters, 1997, 7:337-352.

CETESB - COMPANHIA DE TECNOLOGIA E SANEAMENTO AMBIENTAL. Balneabilidade de Praias e Reservatórios. São Paulo: Cetesb, 2004. Disponível em: <www.cetesb.sp.gov.br>. Acesso em 06/04/2015.

CONAMA - CONSELHO NACIONAL DO MEIO AMBIENTE. Resolução 274/2000.

CONAMA - CONSELHO NACIONAL DO MEIO AMBIENTE. Resolução 357/2005.

GREGHI, S. Q. Avaliação da eficiência de métodos rápidos usados para detecção de Coliformes Totais e Coliformes Fecais em amostras de água em comparação com técnicas de fermentação em tubos múltiplos. Universidade Estadual Paulista, Araraquara, 2005. 
MENEZES, N.A. Aquatic life in the Pantanal de Mato Grosso, Brazil, with special reference to fishes, In Wildlife in the Everglades and Latin American Wetlands (G.H. Dalrymple, W.F. Loftus, F.S. Bernardino, eds.). Abstracts of the Proceedings on the $1^{\circ}$ Everglades National Park Symposium. 1988.

MENEZES, N.A. Methods for assessing freshwater fish diversity. In Biodiversity in Brazil (C.E.M. Bicudo \& N.A. Menezes, eds.). CNPq, São Paulo, 1996. p. 289-295.

MORAIS, R. C. S.; SILVA, C. E. Diagnóstico ambiental do balneário Curva São Paulo no rio Poti em Teresina, Piauí. Engenharia Sanitária Ambiental. v.17, n.1,Janeiro/Março. 2012.

MOURA, A. C.; ASSUMPÇÃO, R. A. B.; BISCHOFF, J. Monitoramento físico-químico e microbiológico da água do Rio Cascavel durante o período de 2003 a 2006. Arquivos do Instituto Biológico, v. 76, n. 1, p. 17-22, 2009.

WHO - WORLD HEALTH ORGANIZATION. Guidelines for a Safe Recreational Water environments, v. 1, Genebra, 2003.

PAVANELLI, C. S. \& CARAMASCHI, E.P. Composition of the ichthyofauna of two small tributaries of the Paraná river, Porto Rico, Paraná State, Brazil. Ichthyol. Explor. Freshwaters, 1997. 8:23-31.

PREFEITURA DE PRESIDENTE PRUDENTE. Disponível em: <http://www.presidenteprudente.sp.gov.br/site/leis decretos.xhtml>. Acesso em 12/04/2015

ROSA, R. S.; GROTH, F. Ictiofauna dos Ecossistemas de Brejos de Altitude de Pernambuco e Paraíba. In: K. C. Pôrto; J. J. P. Cabral; M. Tabarelli (Eds). Brejos de Altitude de Pernambuco e Paraíba. MMA, Brasília. 2004.

REGO, Neylor Alves Calasans; BARROS, Sizínio Rosa; SANTOS, José Wildes Barbosa dos. Avaliação espaço-temporal da concentração de coliformes termotolerantes na lagoa encatada, ilhéus, bahia, brasil. Rede-revista eletrônica do prodema, v. 4, n. 1, 2010.

SABINO, J. \& ZUANON, J.A. A stream fish assemblage in Central Amazonia: distribution, activity patterns and feeding behavior. Ichthyol. Explor. Freswaters, 1998. 8:201-210.

SABINO, J. \& CASTRO, R.M.C. Alimentação, período de atividade e distribuição espacial dos peixes de um riacho da floresta Atlântica (Sudeste do Brasil). Rev. Brasil. 1990. Biol. 50:23-36.

SCHAEFER, S.A. Conflict and resolution: impact of new taxa on phylogenetic studies of the neotropical cascudinhos (Siluroidei: Loricariidae). In Phylogeny and Classification of Neotropical Fishes (L.R. Malabarba, R.E. Reis, R.P. Vari, Z.M.S. Lucena \& C.A.S. Lucena, eds.). EDIPUCRS, Porto Alegre, 1998. p. 375-400.

SOUZA FILHO, E.E. \& STEVAUX, J.C. Geologia e geomorfologia do complexo rio Baía, Curutuba, Ivinheima. In A Planície de inundação do Alto rio Paraná: aspectos físicos, biológicos e socioeconômicos (A.E.A.M. Vazzoler, A.A. Agostinho \& N.S. Hahn, eds.). EDUEM, Maringá, 1997. p. 3-46.

VARI, R.P. \& MALABARBA, L.R. Neotropical Ichthyology: an overview. In Phylogeny and Classification of Neotropical Fishes (L.R. Malabarba, R.E. Reis, R.P. Vari, Z.M.S. Lucena \& C.A.S. Lucena, eds.). EDIPUCRS, Porto Alegre, 1998. p. 1-11. 